\title{
DESIGN AND MANUFACTURING OF SUSTAINABLE CHAISE LONGUE USING PARAMETRIC DESIGN AND ADVANCED ENGINEERING TOOLS
}

\author{
Chaitanya Joshi \\ Director, Professor of Animal Biotechnology, \\ Gujarat Biotechnology Research Centre, India
}

\begin{abstract}
Using advanced computer aided design (CAD) and computer aided engineering (CAE) tools assists designers with the shape conceptualization and detailed drawings, virtual testing, and downstream manufacturing activities. Manufacturing process plans, using computer aided manufacturing (CAM) software, are developed from these $C A D$ files. In this paper I developed parametric design of sustainable chaise lounge and developed actual manufacturing and assembly process plan. For making my design successful in finite element analysis I made two iteration and second design was able to withstand against load of more than 264 lbs which was result of finite element analysis in Catia. This is proper representation of innovative design integrated with advanced machining and process planning.
\end{abstract}

Key words: Multi-layered cardboard sub-components; parametric model; modular design; design for assembly; finite element modeling

Cite this Article: Chaitanya Joshi, Design and Manufacturing of Sustainable Chaise Longue Using Parametric Design and Advanced Engineering Tools, International Journal of Design and Manufacturing Technology (IJDMT),11(1), 2020, pp. 15-26. https://iaeme.com/Home/issue/IJDMT?Volume=11\&Issue $=1$

\section{INTRODUCTION}

There are many furniture styles employed for sitting and resting. One style used for resting in a partially reclined position is a 'chaise lounge', which is the focus of this work. When designing furniture, functionality and fashion are both core elements. Sustainability and ergonomics are contemporary additional design criteria.

There are a wide variety of designs and materials used to fabricate chaise lounges, but there are some consistent shape characteristics, as shown in Figure 1. A chaise lounge consists of proper room for a leg rest, a seat, and an inclined back rest conditions. Anthropometric (i.e., body dimensions) considerations are core for effective furniture design, and companies such as All steel promote leveraging anthropometric databases, and ergonomic principles when designing their furniture. Consequently, the essential shape dimensions, and the 
adjustable design parameters reflect data available at the CDC "Anthropometric Reference Data for Children and Adults: United States, 2007-2010"

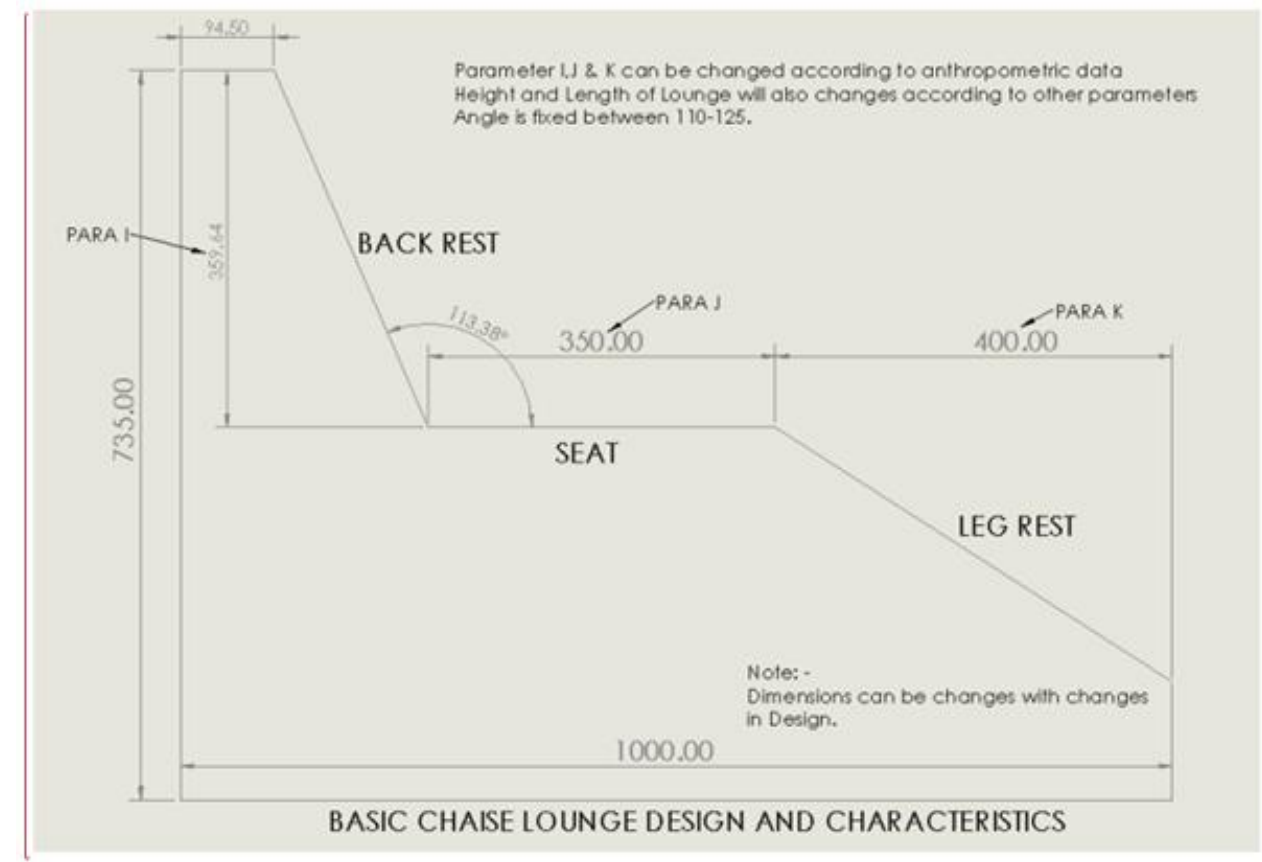

Figure 1 Chaise lounge Structure

A chaise lounge can be fabricated using a variety of materials. However, an alternative approach is being presented here. The goal for this research is to employ a cardboard based solution for the frame and the body. In addition to using cardboard, which can consist of repurposed boxes, a modular design approach is presented, and other advanced design considerations. This includes considering the interchangeability of the sub-components, parametric shape control, and a strong and lightweight design, which also respects ergonomic design elements. Fabric coverings and cushion design and fabrication is out of scope for this work.

Different techniques are used to select a proper material for product. Life cycle assessment is the index which gives us an idea about effects of material on environment through its life span, processing resources, manufacturing, distribution, use, recycling and disposal (Bovea, n E-12071, \& Vidal, 2004).

The potential materials that can be utilized at presented in Table 1. Wood, which is costly and heavy, has a good yield strength (but the strength characteristics are anisotropic), and is durable. The harvesting, transport, and preparation (drying, blanking, etc.) requires significant energy and introduces waste, and the disposal is an issue. Consequently, this material can be considered environmentally unfriendly although this research is replenishable.

Bovea and Vidal, (2004 compared several wood based boards including low and high density laminates, and wood veneers. The fiberboard laminate construction included resin with a formaldehyde content. These materials are analyzed with the SIMA pro V4 software and the Eco0-Indicator99 method is used. They determined that low density laminates are preferred (from an environmental perspective) compared with the high density material. However, the study is limited to these three materials. They did not evaluation the process of acquiring the dry natural veneer.

An alternative to wood is bamboo, which has been evaluated from a sustainable economic development perspective (Nishimura, 2004). Bamboo is a fasting growing plant and is used in 
Design and Manufacturing of Sustainable Chaise Longue Using Parametric design and advanced Engineering tools

furniture, and Nishimura considers this as an underutilized resource. The manufacturing cost, recycling cost and disposal cost for bamboo is very low compared to petroleum resources.(Leamlaksakul, 2008) performed several simulations for static, impact and dynamic loading cases using a multi-physics FEA solver to improve the designs for laminated bamboo chairs.

Metals, such as stainless steel, wrought iron, and aluminum are utilized for furniture, and these materials are cheaper when compared to wood. They have high strength, and less is required to create a skeleton body; however, if the surface geometry is manufactured from these materials, the chaise lounge will be heavy. These materials can be readily recycled, but there is extensive energy required to refine the materials and provide initial shape blanks. Plastics, such as PVC, can also be used. Plastic is very low cost, has moderate strength characteristics, and is easy to carry or rearrange with compared to the other two material families as it is very light weight. It is not attractive compared when compared to the other options, and is environmentally unfriendly as it does not readily degrade. Modular designs have been observed for the wood and metal based furniture options for chaise lounges, but not for plastic. Specialty resins can be employed to improve the aesthetic look of a chair.

The manufacturing costs must also be considered. For metal based solutions, high energy processes such as stamping, bending, welding, and machining are employed, and for the wood based options, CNC routers and specialty wood working processes are utilized.

Table 1 Summary of Different Material

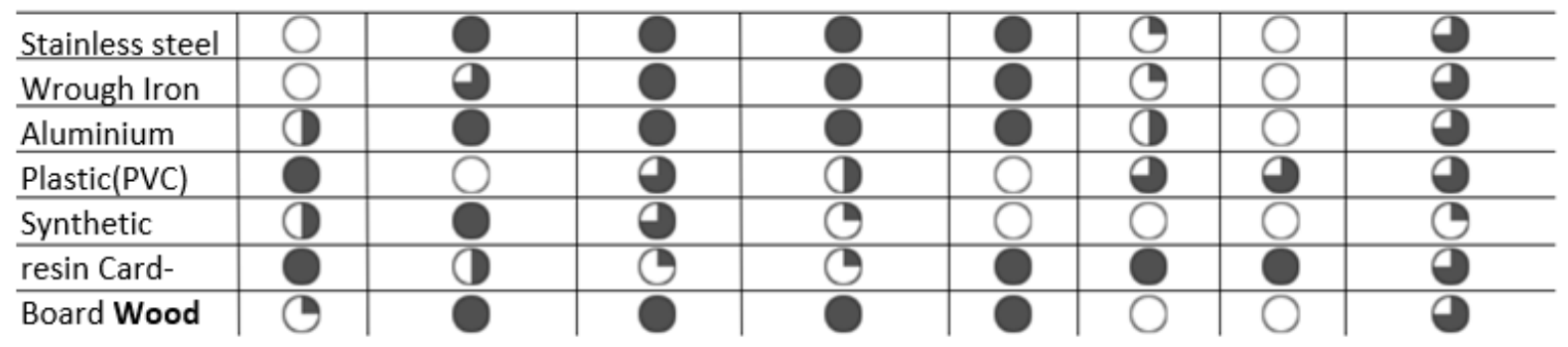

Sustainability issues are a concern in the furniture industry, and is being addressed through many perspectives. However, published research is limited for this topic. (Petutschnigg, 2007) have indicated in their research that paper panels can be used to replace wooden furniture. Their research focus was on lightweight paper panels and tubes. Panels with a honeycomb core and tubes with different joint configurations were analyzed and evaluated via bending tests and compared to wooden furniture. Their results indicated that a sandwich approach, using high density fiberboards were glued onto the panels, can bear high loads. These researchers showed that a paper based solution is appropriate for furniture applications when using a multi-layering approach.

From the literature review, it is apparent that there is interest in different furniture design and manufacturing solutions, but little research has been done exploring cardboard based furniture designs. Sani (2016) utilized shredded cardboard waste by designing a cardboard bench for two people, but this is a conceptual idea. A 'Cardboard Chair' challenge is a lesson plan at MIT. Students have presented designs that are easy to assembly and dissemble, and that are aesthetically pleasing. Researchers have targeted a lamination approach to improve strength, and joint design is a concern.

Consequently, the goal of this research is to develop a modular design for a cardboard chaise lounge that has the necessary strength characteristics, while using the minimum amount of cardboard. It is to be lightweight, but not bend due to improper supports for a 
person's weight distribution. Proper joint designs must be considered to reduce tear and bending damage.

Solid works and CATIA V5 are utilized to develop and analyze 3D models. These $\mathrm{CAD} / \mathrm{CAE}$ tools, along with reverse engineering, are used to optimize the design. This is presented in section Third section.

The results are presented in section result and discussion, and the conclusions is in last section. A review of related manufacturing methods is presented in the next section.

\section{MANUFACTURING METHODS LITERATURE REVIEW}

There are number of ways for approaching the design challenges and fabrication for the chaise lounge. The reviewed literature included information related to material selection, design methodologies, ecological design cycles, and manufacturing methodologies. (Hunter, 2008)who implemented the Toyota Production System (TPS) for the furniture industry, focuses on the reduction of waste or muda (uselessness) during the manufacturing process. These 'wastes' include transportation, inventory, motion or waiting, over-production and over-processing, as well as defects. Hunter developed a Double D manufacturing cell for recliners, as this this layout reduces waste. Considering a TPS and complementary lean manufacturing strategy should be implemented.

The Group Technology (GT) is method of development of work cell by grouping similar parts together. (Suzic\&acute, et al., 2012)also implemented different manufacturing technologies such as Hunter for furniture production. To achieve mass customization, they used a group technology approach. In their GT case study, they performed research on a Serbian furniture making company and its customers. They analyzed the product assortment, the machine line-up, the material flow and the technological capabilities of the machines. They categorized 440 parts into 16 families. They created flow diagrams for the material flow, for the part groups, and different type of correlation matrixes for achieving customization and designing a new plant layout to optimize the machine utilization and flows. This approach is more applicable for a comprehensive product set.

Another related research contribution assesses the impact of manufacturing on the environment. The authors (Iritani, et al., 2015)describe the use of remanufacturing and adaptive manufacturing technology for maintaining the product value and minimizing waste. They evaluated steel office furniture for Davies Inc for their adaptive design and remanufacturing process over multiple remanufacturing cycles and compared the environmental impact of remanufactured steel furniture of other companies. They evaluated their results based on life cycle assessment. (Adaptive remanufacturing for multiple lifecycles: A case study in office furniture). Remanufacturing extends the life of a product, and a future work activity would be to explore this approach for a cardboard furniture suite of products.

This literature describes the development of manufacturing processes for producing furniture with minimum waste. This information is summarized in Table 2. The key points related to the minimizing manufacturing waste and sustainable furniture are included, where $\mathrm{x}$ - this topic is not addressed and $\checkmark$-this topic is addressed. This research gap for a cardboard solution is addressed in this paper. 
Design and Manufacturing of Sustainable Chaise Longue Using Parametric design and advanced Engineering tools

\begin{tabular}{|c|c|c|c|c|c|c|c|}
\hline Literature Reviewed & $\begin{array}{c}\text { Mechancial } \\
\text { Sustainable Design }\end{array}$ & $\begin{array}{l}\text { Manufactruing } \\
\text { Techniques }\end{array}$ & $\begin{array}{c}\text { Selection of } \\
\text { Material }\end{array}$ & $\begin{array}{c}\text { Ecological } \\
\text { Design }\end{array}$ & Ecomonics & Authors & Comments \\
\hline $\begin{array}{l}\text { Lightweight paper materials for } \\
\text { furniture - A design study to develop } \\
\text { and evaluate materials and joints }\end{array}$ & $\checkmark$ & $\mathbf{x}$ & $\checkmark$ & $\downarrow$ & $\boldsymbol{x}$ & $\begin{array}{l}\text { Alexander } \\
\text { Johannes } \\
\text { Petutschnigga } \\
\text { Michael Ebnerb }\end{array}$ & $\begin{array}{c}\text { Based on material } \\
\text { and design } \\
\text { technologies }\end{array}$ \\
\hline $\begin{array}{l}\text { The Role of Bamboo in the Sustainable } \\
\text { Economic Development: From a } \\
\text { Viewpoint of Social Common Capital }\end{array}$ & $x$ & $\mathbf{x}$ & $\downarrow$ & $\downarrow$ & $\checkmark$ & Osamu Nishimura & $\begin{array}{l}\text { Need more detail } \\
\text { for designing } \\
\text { manufacturing }\end{array}$ \\
\hline $\begin{array}{l}\text { Materials selection for sustainable } \\
\text { product design: a case study of wood } \\
\text { based furniture eco-design }\end{array}$ & $x$ & $\checkmark$ & $\checkmark$ & $x$ & $\boldsymbol{x}$ & $\begin{array}{l}\text { María D.Bovea } \\
\text { RosarioVidal }\end{array}$ & $\begin{array}{c}\text { Best for selection } \\
\text { of material }\end{array}$ \\
\hline $\begin{array}{c}\text { Oblog Cardboard Furniture : The } \\
\text { Exploration of Cardboard for Bench } \\
\text { Design }\end{array}$ & $\checkmark$ & $\boldsymbol{x}$ & $\checkmark$ & $\checkmark$ & $\mathbf{x}$ & $\begin{array}{l}\text { Mohd Najib } \\
\text { Abdullah Sani }\end{array}$ & $\begin{array}{l}\text { Not focused on } \\
\text { Mfg. }\end{array}$ \\
\hline $\begin{array}{l}\text { Creating and Researching Sustainable } \\
\text { design of corrugated cardboard } \\
\text { furniture with advanced technological } \\
\text { means }\end{array}$ & $\nu$ & $x$ & $\boldsymbol{x}$ & $\checkmark$ & $\boldsymbol{x}$ & $\begin{array}{l}\text { Dovramadjiev } \\
\text { Jecheva Bratanov } \\
\text { Cankova }\end{array}$ & $\begin{array}{l}\text { Proper } \\
\text { presentation of } \\
\text { New product } \\
\text { development }\end{array}$ \\
\hline $\begin{array}{l}\text { Toyota production system applied to } \\
\text { upholestery furniture manufacturing } \\
\text { industry }\end{array}$ & $\checkmark$ & $\checkmark$ & $\boldsymbol{x}$ & $x$ & $\checkmark$ & Steve L. Hunter & $\begin{array}{l}\text { Implementation } \\
\text { of Lean tool in } \\
\text { Furniture }\end{array}$ \\
\hline $\begin{array}{l}\text { Customizing products through } \\
\text { application of group technology: A } \\
\text { case study of furniture manufacturing }\end{array}$ & $\boldsymbol{x}$ & $\checkmark$ & $\boldsymbol{x}$ & $x$ & $\downarrow$ & $\begin{array}{c}\text { Nikola Suzić } \\
\text { Branislav } \\
\text { Stevanov Ilija } \\
\text { Cosic Zoran Anišić } \\
\text { Nemanja Sremčev }\end{array}$ & \\
\hline $\begin{array}{l}\text { Adaptive remanufacturing for multiple } \\
\text { lifecycles: A case study in office } \\
\text { furniture }\end{array}$ & $x$ & $\checkmark$ & $\boldsymbol{x}$ & $x$ & $\downarrow$ & $\begin{array}{l}\text { Mark Krystofik } \\
\text { Allen Luccitti Kyle } \\
\text { Parnell Michael } \\
\text { Thurston }\end{array}$ & \\
\hline
\end{tabular}

Figure 2 Comparison of Literature

Nowadays people are developing and purchasing eco-friendly products. The amount and usage of the cardboard needs to be considered. This influences the manufacturing process and the resulting product quality. The improper selection of the material thicknesses may cause tears and other defects (i.e., bending). Part interchangeability leads to waste minimization and reduces the product costs. a design and build solution for modular, parametric chaise lounge configurations is presented. The design, analysis, and prototyping approaches are discussed in the next section.

\section{METHODS}

Development of parametric design using design software such as Solidworks and Catia V5. Taking reference of functional parameter and characteristics from http://dapurauto.com/gaske/ and made two model.

Firstly, developed Recliner which is compact in design and dimension are taken from above website but this design possesses improper distribution of space for seating arrangement. Leg rest is very small and it is below the seat which increases issues regarding comfort we dropped idea of making recliner and for providing strength to chair we need plenty of Card board which increases cost.

After more research we move forward to create portable chaise lounge with least amount of parts and we adopt reverse engineering for defining parts. First cut parts according to anthropometric size charts and create assemblies. After three iteration we finally decided number of parts and its size. Then we modelled our design in solidworks.

Our Lounge possesses total 14 numbers of parts in which are divided into 8-part families for achieveing customization. 


\section{RESULTS}

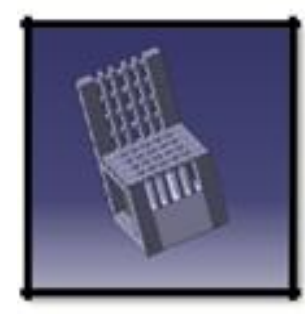

Figure 3 Initial Recliner chair

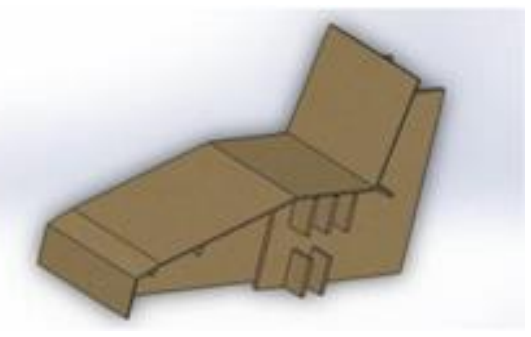

Figure 4 Final Design of Chaise longue

\subsection{FEA results}

Used CATIA V5 for FEA, used generative structure analysis, Highest stress on bottom and top spacer, Results can contain weight of $956.148375 \mathrm{~N}$, Size of mash is $5 \mathrm{~mm}$ and $2 \mathrm{~mm}$ in leg zone and bottom.
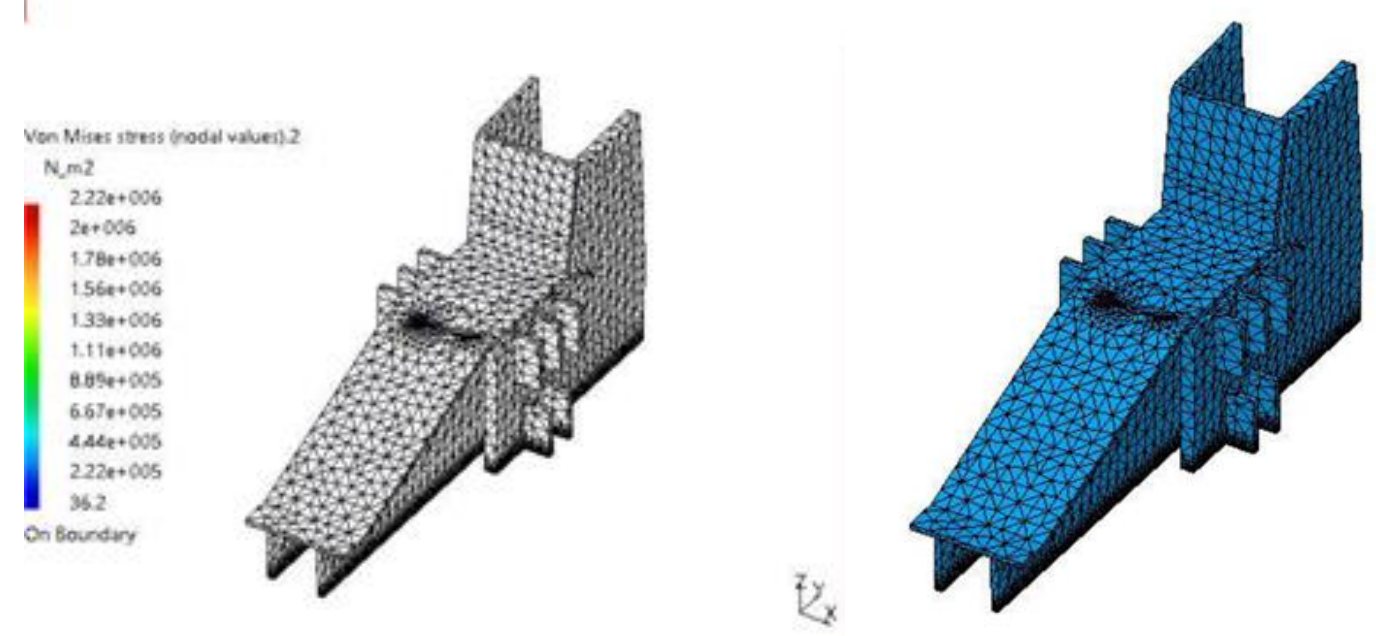

Yield strength of cardboard increased by appropriate design

Different thickness card board results in even weight distribution

Thickness of Cardboard is $15 \mathrm{~mm}$ we developed design with 12 and $9 \mathrm{~mm}$ but it is not able to withstand

For making more than one variant, Flexible system can be adopted

It is flexible design; Chaise lounge can easily have converted in to simple chair by removing leg rest frame. Time taken for assembly is around $67 \mathrm{Sec}$.

\section{Design for assembly results (disassemble \& reassemble)}

Surface Protector -10

Parts included - Main frame left -1 
Design and Manufacturing of Sustainable Chaise Longue Using Parametric design and advanced Engineering tools

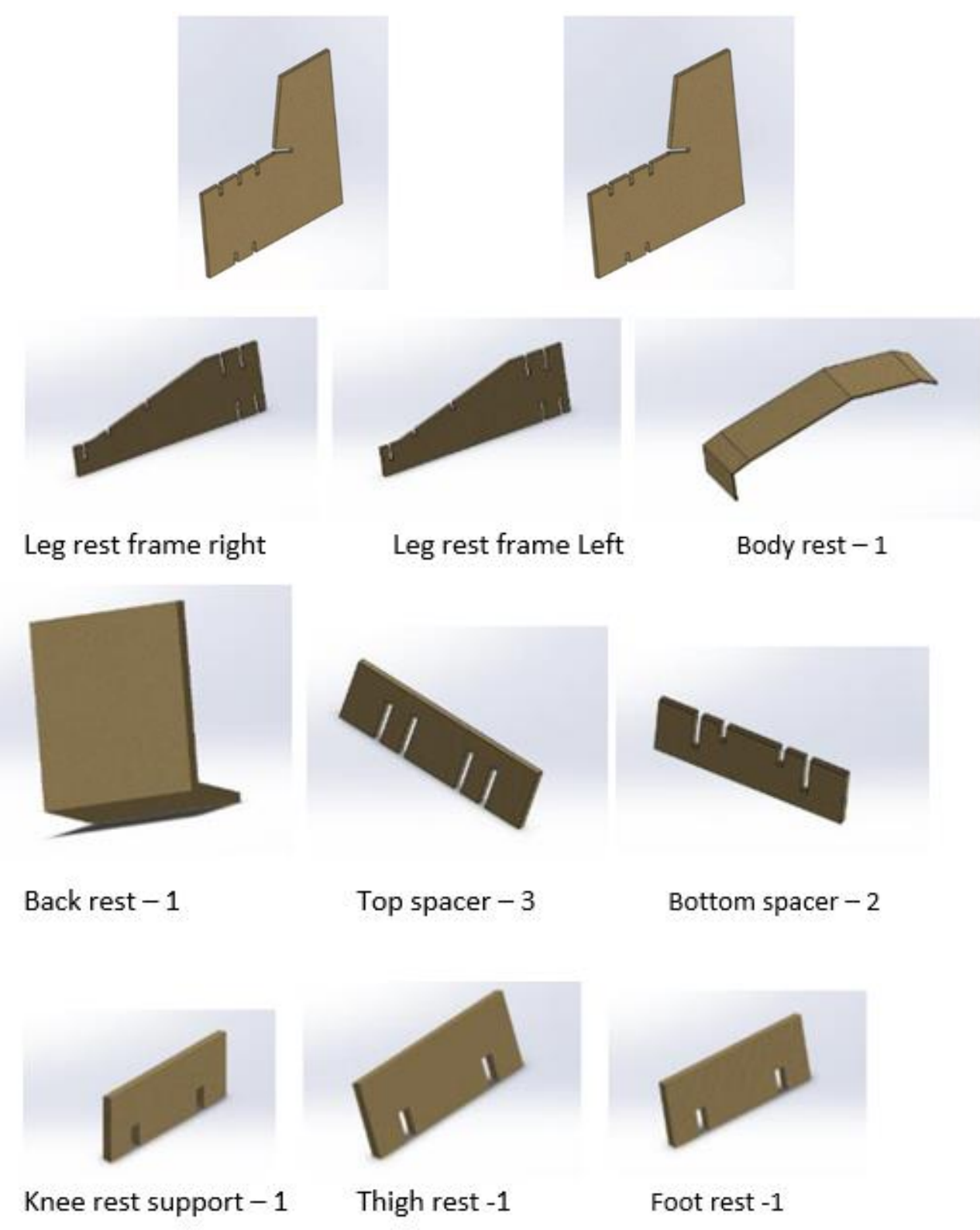

Carefully remove the components from the box then remove the plastic cover from the components to assemble the components of the chair

Find a flat surface on which the chair can be assembled

\section{Step-1}

Take the main frame 1 and place it upright on the floor

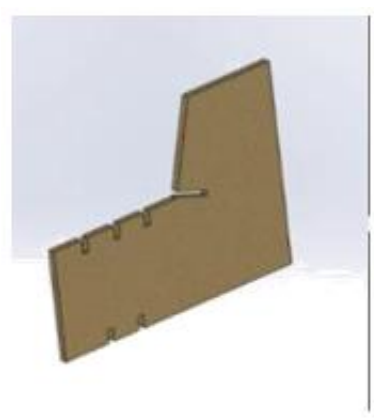




\section{Step- 2}

Take the main frame 2 and place it upright parallel to frame 1 both the frame should look as described in the picture

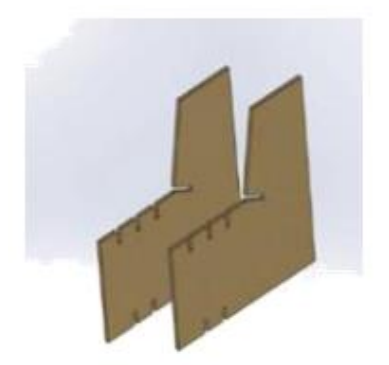

\section{Step -3}

Take the bottom spacer 1 and place it below both the main frame in the first slot provided which is provided downwards as shown in picture

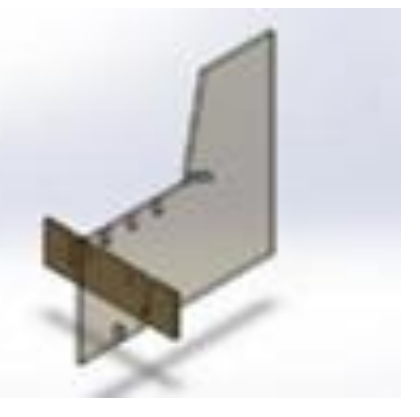

\section{Step - 4}

Repeat the same process with the bottom spacer 2 and place it in the second hole of the two main frame picture

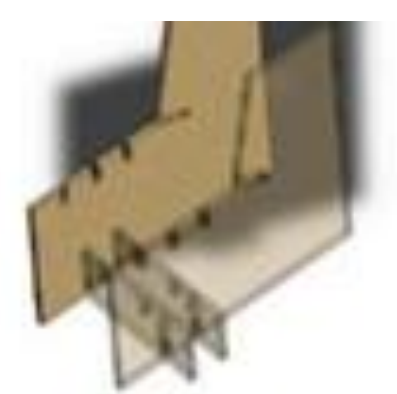

The assembly will stand on its won and the further process are shown below

\section{Step -5}

Take 1 of the leg frame and place it between the main frame it should slide in the slot provided in the bottom spacer. Picture 
Design and Manufacturing of Sustainable Chaise Longue Using Parametric design and advanced Engineering tools

\section{Step-6}

Take another leg frame and place it between two upright main frames parallel to first leg frame and slide it in the slots of the two bottom spacers picture

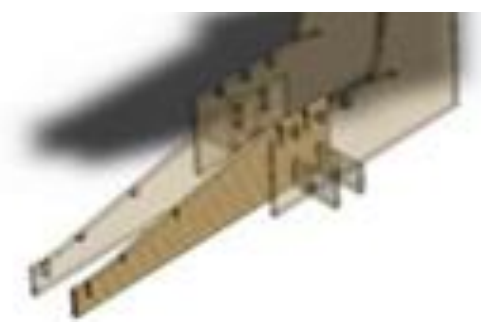

\section{Step-7}

Take 1 of the top spacer and place it on the first slots of two upright main frame

\section{Step-8}

Take second top spacer and place it on the second slots of two upright main frame and second slots of two upright leg frame picture

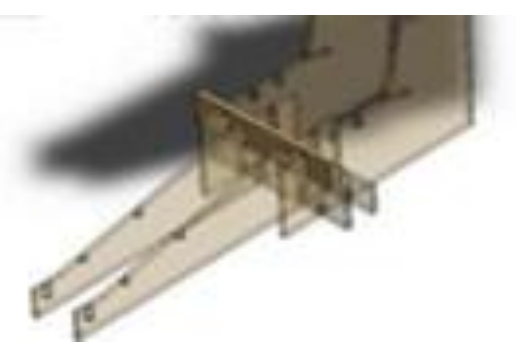

\section{Step-9}

Take the third top spacer and place it on the slots of the two upright main frame and two upright leg frame similar to step-8

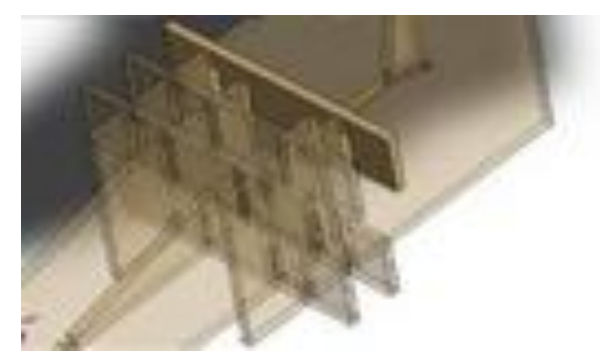

\section{Step-10}

Place the thigh spacer between the first slots on the leg frame picture

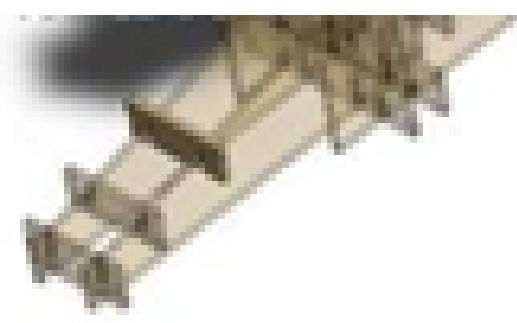




\section{Step-11}

Place the knee spacer between the second slots on the leg frame

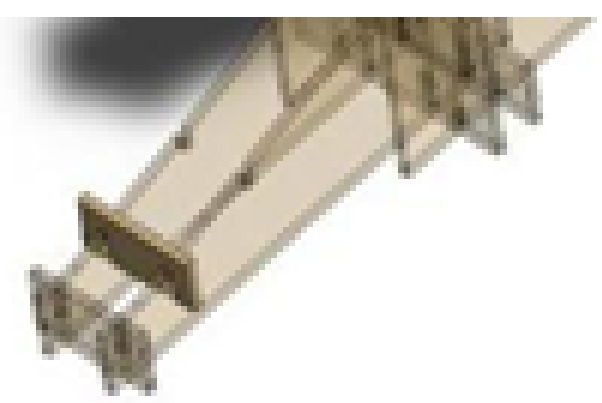

\section{Step-12}

Place the foot rest on the third slot of the leg frame

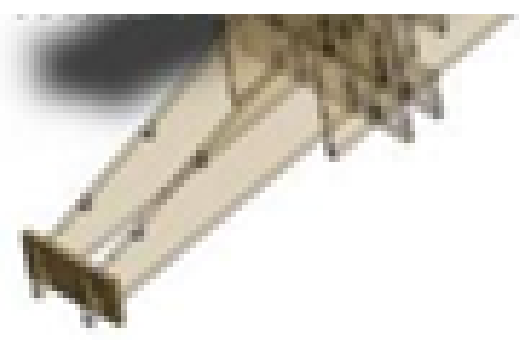

NOTE-the main frame of the chair is ready and should look like the picture below Step-13

Place the back rest hold it in such a way that the longest edge slides in to the side slots of two main frames picture

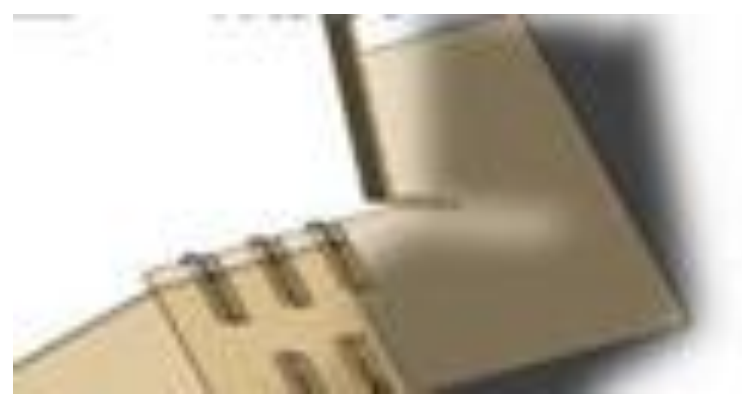

\section{Step- 14}

Take the body rest and place it on the frame of the chair as shown in figure below

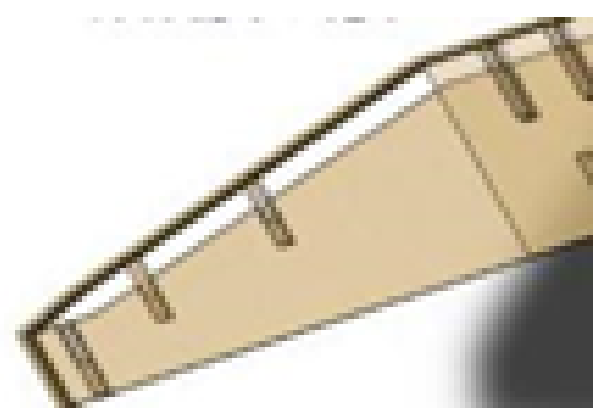


Design and Manufacturing of Sustainable Chaise Longue Using Parametric design and advanced Engineering tools

\section{Step -15}

Place all the surface protector the side of cardboard touching the floor

\section{DISCUSSIONS}

\subsection{Manufacturing}

There are two methods that can be used for manufacturing parts.

1. CNC cutting machine for the cardboards

2. CNC laser cutting machine

e used CNC Laster cutting machine because it is very fast, precise and cheap for high amount of part.

Due to laser cutting operation the need of jigs and fixture are nil we just need magnets to hold the card board on workbench.

Measurement of parts are very important in any manufacturing process. For 14 parts we just need to inspect 8 parts all other parts are identical. The measurement needs to be checked are length, width, thickness and notch size. For that on early stage we develop Go/No-go Gauges according to nesting and passing part from it. For measuring thickness, we will use Vernier caliper.

According to research paper of manufacturing technologies we developed manufacturing process flow diagram.

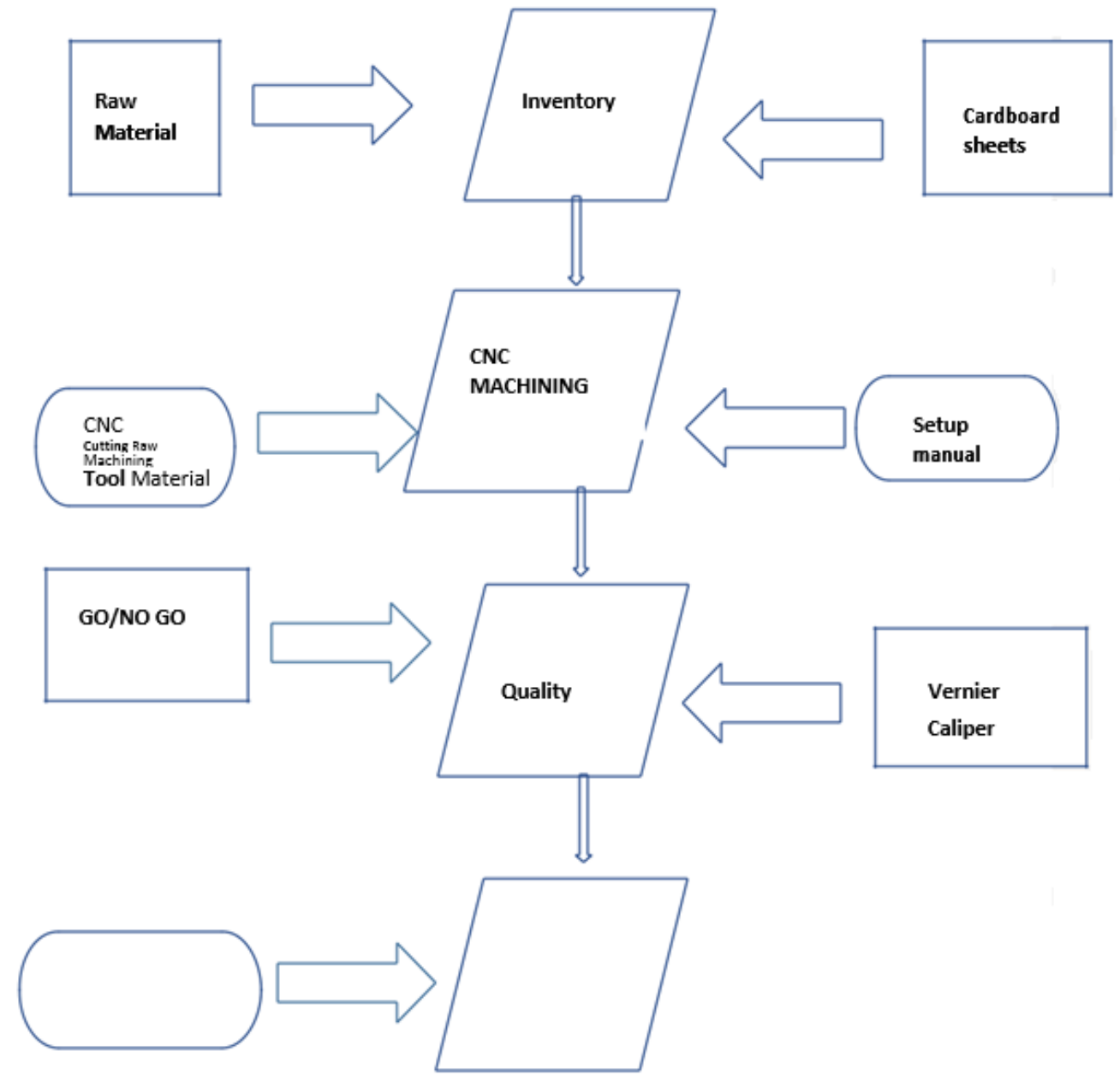

New expanded products 


\section{Optimization}

For nesting is done in modeling software so that we get the optimized solution for nesting the parts in a cardboard sheet. it requires 1.5 sheet for machining all the parts for an assembly.

\section{SUMMARY AND CONCLUSIONS}

Modular design, easy to carry, high yield strength, Cost-effective, easily turn into simple chair (Reduction in floor requirement), Use of more and more eco-friendly product. After two iteration of design I reached on conclusion that in near future people will move towards eco friendly ear with innovation of design and this product can be fulfill their all needs, and desires compare with simple chair. With the use of advanced technology, we can create cheap and unique manufacturing process for different product. Several which use the CAD files as input, are automated for cabinetry, and related 2D wood working undertakings.

\section{REFERENCES}

[1] Bovea, (o., n E-12071, S., \& Vidal. (2004). Materials selection for sustainable product design: A case study of wood based furniture eco-design. : Materials and Design, $v 25, n$ 2, $111-116$.

[2] Hunter, S. L. (2008). The toyota production system applied to the upholstery furniture manufacturing industry. Materials and Manufacturing Processes, $v 23, n$ 7, 629-634.

[3] Iritani, D. (, o Carlos School of Engineering, U. o., o Paulo, 4. T., o-Carlense Avenue, S., Carlos, o., 13566-590, B., Grael, P. (2015). Sustainable strategies analysis through Life Cycle Assessment: A case study in a furniture industry. Journal of Cleaner Production, $v$ 96, 308-318.

[4] Leamlaksakul, V. (2008). Innovative Design of Laminated Bamboo. Retrieved from International Journal of Mathematics and Computers in Simulation: http://www.naun.org/main/NAUN/mcs/mcs-98.pdf

[5] Nishimura, O. (.-8. (2004). The role of bamboo in the sustainable economic development: From a viewpoint of Social Common Capital. JSME International Journal, Series A: Solid Mechanics and Material Engineering, v 47, n 4, 527-532.

[6] People Survey . (n.d.). Retrieved from U.S. Department of Health and Human Services:

[7] https://www.cdc.gov/nchs/data/series/sr_11/sr11_252.pdf

[8] Petutschnigg, A. J.-5. ( 2007). Lightweight paper materials for furniture - A design study to develop and evaluate materials and joints. Materials and Design, v 28, $n 2$, 408-413.

[9] Suzic, Nikola, Branislav Stevanov, Ilija Cosic, Zoran Anisic, \& Nemanja Sremcev. "Customizing Products through Application of Group Technology: A Case Study of Furniture Manufacturing." Strojniski Vestnik / Journal of Mechanical Engineering [Online], 58.12 (2012): 724-731 